\title{
Evaluation of Nootropic Effect of Argyreia speciosa in Mice
}

\author{
Joshi Hanumanthachar, ${ }^{*, a}$ Kaur Navneet, ${ }^{b}$ and Chauhan Jyotibala \\ ${ }^{a}$ Department of Pharmacognosy, SET's College of Pharmacy, S. R. Nagar, Dharwad-580002, Karnataka, India and ${ }^{b}$ Department of \\ Biotechnology, Pooja Bhagavat Memorial Mahajana's P. G. Centre, Mysore, Karnataka, India
}

(Received January 27, 2007; Accepted April 12, 2007)

\begin{abstract}
Dementia is a brain disorder that seriously affects a person's ability to carry out daily activities. The most common form of dementia among older people is Alzheimer's disease (AD), which initially involves the parts of the brain that control thought, memory, and language, ending with severe brain damage. Nootropic agents like, piracetam, and cholinesterase inhibitors like, donepezil are commonly used for improving memory, mood and behavior but their adverse effects have made their use limited and it is worthwhile to explore the utility of traditional medicines in the treatment of various cognitive disorders. Argyreia speciosa (AS) commonly known as Vridha daraka is widely used in ayurveda for the treatment of neurological disorders. The present work was undertaken to assess the potential of AS as a nootropic and anti-cholinesterase agent in mice. Effectiveness of aqueous extract of AS on ageing, scopolamine and diazepam induced memory deficits in mice was evaluated. Elevated plus maze and passive avoidance paradigm were employed to assess short-term and long term memory. In order to delineate the possible mechanism through which AS elicits the anti-amnesic effects, the whole brain acetyl cholinesterase (AChE) activity, was also assessed. Two doses (100 and $200 \mathrm{mg} / \mathrm{kg}$, p.o.) of aqueous extract of AS were administered orally for 6 successive days to both young and aged mice. AS decreased transfer latencies and increased step down latencies in both young and aged mice AS (100 and $200 \mathrm{mg} / \mathrm{kg}$, p.o.) successfully reversed amnesia induced by diazepam, scopolamine and natural ageing. AS significantly decreased AChE levels in the whole brain homogenate indicating its potential in the attenuation of learning and memory deficits especially in the aged mice.
\end{abstract}

Key words — amnesia, learning, Argyreia speciosa, acetyl cholinesterase, nootropic, ayurveda

\section{INTRODUCTION}

Alzheimer's disease (AD), the most common form of dementia in the elderly population, is characterized by an insidious onset with memory impairment and an inexorable progression of cognitive decline. Neuropathological examination of AD brain reveals extensive atrophy, accumulation of intraneuronal neurofibrillary tangles, ${ }^{1)}$ and $\beta$-amyloid $(\mathrm{A} \beta)$ fibrillar deposists $(\mathrm{A} \beta \text { plaques })^{2)}$ in vulnerable regions of the brain (e.g. cortex, hippocampus). Researchers estimate that by 2050, 13.2 million Americans will have AD if current population trends continue and no preventive treatments become available. ${ }^{3)}$ Approximately 4 million Americans are of age 85 years or older, the age group which is one of the fastest growing segments of the population. Ayurvedic medicinal plants had suc- cessfully attenuated memory dysfunction induced by scopolamine, ethanol and diazepam. ${ }^{4)}$ Argyreia speciosa (Abbreviation; Family Convolvulaceae), is commonly known as Vridha daraka in Sanskrit. It is a large climber grown throughout India. It is one of the important plants used in indigenous system of medicine. The root is regarded as an alternative tonic and useful in rheumatism and diseases of the nervous system. ${ }^{5)}$ It is reported to possess anti-inflammatory, anti-arthritic, ${ }^{6)}$ immunomodulatory $^{7)}$ and anti-stress activity. ${ }^{8)}$ In the present study AS was investigated for its potential as a nootropic agent. Elevated plus maze and passive avoidance paradigm were used to assess short-term and long term memory respectively. To delineate the mechanism by which AS exerts nootropic action, its effect on brain acetyl cholinesterase levels was determined.

*To whom correspondence should be addressed: Department of Pharmacognosy, SET's College of Pharmacy, S. R. Nagar, Dharwad-580002, Karnataka, India. Tel.: +91-9448632253; Fax: +91-836-2448540; E-mail: amanjoshi17@yahoo.com 


\section{MATERIALS AND METHODS}

The Plant Material and Preparation of Extract — The roots of AS (A. nervosa Burm; Family Convolvulaceae) were obtained from Dharwad, Karnataka, India. The plant was authenticated and identified by qualified botanist at Department of Botany, Karnataka University, Dharwad. The specimen has been kept at Dept. of Pharmacognosy, SET'S college of Pharmacy, Dharwad, Karnataka, India. The roots were dried in shade; cleaned, powdered and aqueous extract was prepared by simple maceration process using $1000 \mathrm{~g}$ of powder. The extract was concentrated using rotary flash evaporator followed by freeze drying. The yield of the dry extract from crude powder of $A$. speciosa was $1.5 \%$. A suspension was prepared using tween 80 and administered orally.

Drugs and Chemicals - Scopolamine hydro bromide (Sigma Aldrich, Lt. Louis, MO, U.S.A.), diazepam (Valium ${ }^{\circledR}$, Ranbaxy laboratories Ltd., Mumbai, India), piracetam (Nootropil ${ }^{\circledR}$ UCB India pvt. Ltd., Vapi, India) and phenytoin (Zydus Neurosciences, Ahmedabad, India) were diluted in normal saline and injected intraperitoneally (i.p.). Volume of injection was $1 \mathrm{ml} / 100 \mathrm{~g}$ body weight of the mouse.

Animals — Swiss mice of either sex weighing around $18 \mathrm{~g}$ (younger, 8 weeks old) and $25 \mathrm{~g}$ (older, 28 weeks old) were used in the present study. Animals were procured from disease free animal house, BLDEA Medical College, Bijapur. They were acclimatized to the laboratory conditions for 5 days before behavioral studies. The animals had free access to food and water and maintained under $12: 12 \mathrm{hr}$ light and dark cycles. All experiments were carried out during day time from 0900 to $1900 \mathrm{hr}$. The Institutional Animals Ethics Committee (IAEC) approved the experimental protocol and care of animals was taken as per guidelines of Committeee for the Pupose of Control and Supervision on Experiments on Animals (CPCSEA), Dept. of Animal Welfare, Govt. of India.

\section{Memory Models \\ Exteroceptive Behavioral Model}

Elevated plus maze: The elevated plus maze served as the exteroceptive behavioral model (where in stimulus existed outside the body) to evaluate learning and memory in mice. ${ }^{9)}$ The apparatus consists of two open arms $(16 \times 5 \mathrm{~cm})$ and two covered arms $(16 \times 5 \times 12 \mathrm{~cm})$. The arms extended from a central platform $(5 \times 5 \mathrm{~cm})$, and maze is elevated to a height of $25 \mathrm{~cm}$ from the floor. On the first day, each mouse was placed at the end of open arm, facing away from the central platform. Transfer latency (TL) was taken as the time taken by mouse to move into one of the covered arm with all its four legs. TL was recorded on the first day. If the animal did not enter into one of the covered arms within $90 \mathrm{~s}$, it is gently pushed into one of the two covered arms and the TL was assigned as $90 \mathrm{~s}$. The mouse was allowed to explore the maze for $10 \mathrm{~s}$ and then returned to its home cage. Memory retention was examined on the second day, $24 \mathrm{hr}$ after the first day's trial. $^{10-12)}$

Passive shock avoidance paradigm: Passive avoidance behavior based on negative reinforcement was used to examine the long term memory. The apparatus consisted of a box $(27 \times 27 \times 27 \mathrm{~cm})$ having three walls of wood and one wall of Plexiglas, featuring a grid floor $(3 \mathrm{~mm}$ stainless steel rods set $8 \mathrm{~mm}$ apart), with a wooden platform $(10 \times 7 \times 1.7 \mathrm{~cm})$ in the center of the grid floor. The box was illuminated with a $15 \mathrm{~W}$ bulb during the experimental period. Electric shock $(20 \mathrm{~V} \mathrm{AC})$ was delivered to the grid floor. Training was carried out in two similar sessions. Each mouse was gently placed on the wooden platform set in the center of the grid floor. When the mouse stepped down and placed on the wooden platform set in the center of the grid floor. When the mouse stepped down and placed all its paws on the grid floor, shocks wee delivered for $15 \mathrm{~s}$ and the step-down latency (SDL) was recorded. SDL was defined as the time taken by the mouse to step down from wooden platform to grid floor with its entire paw on the grid floor. Animals showing SDL in the range (2-15 s) during the first test were used for the second session and the retention test. The second-session was carried out 90 min after the first test. When the animals stepped down before $60 \mathrm{~s}$, electric shocks were delivered for $15 \mathrm{~s}$. During the second test, animals were removed from shock free zone if they did not step down for a period of $60 \mathrm{~s}$. Retention was tested after $24 \mathrm{hr}$ in a similar manner, except that the electric shocks were not applied to the grid floor. Each mouse was again placed on the platform, and the SDL was recorded, with an upper cut-off time of 300 s. $^{13,14)}$

Estimation of Brain Acetyl Cholinesterase (AChE) Activity — On the $7^{\text {th }}$ day the animals were euthanized by cervical dislocation carefully to avoid any injuries to the tissue. The whole brain AChE activity was measured using the Ellman method. ${ }^{15)}$ The end point was the formation of 


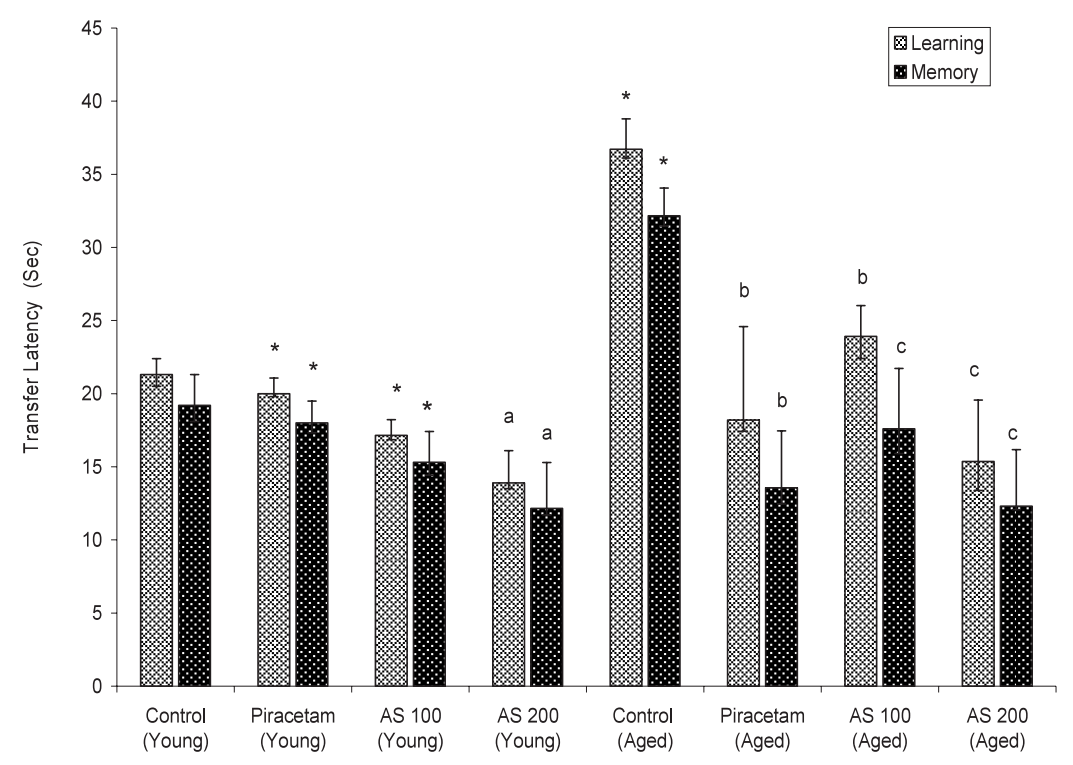

Fig. 1. Effect of AS on TL of Young and Aged Mice. Piracetam (200 mg/kg, i.p.) was Used as Standard Drug

Values are Mean $\pm \operatorname{SEM}(n=5)$, ANOVA followed by Tukey-kramer test. ${ }^{*} p<0.01$ compared to control (Young mice), $\left.a\right) p<0.001$ compared to control (Young mice), $b) p<0.01$ compared to control (Aged mice), $c$ ) $p<0.001$ compared to control (Aged mice).

yellow color due to the reaction of thiocholine with dithiobisnitrobenzoate ions. The rate of formation of thiocholine from acetylcholine iodide in the presence of tissue cholinesterase was measured using a spectrophotometer. The sample was first treated with 5,5'-dithionitrobenzoic acid (DTNB) and the optical density (OD) of the yellow color compound formed during the reaction at $412 \mathrm{~nm}$ every minute for a period of three minutes was measured. Protein estimation was done using Lowry's (Folin-phenol reagent) method. ${ }^{25)}$ AChE activity was calculated using the following formula:

$$
\mathrm{R}=\frac{\delta \text { O.D. } \times \text { Volume of Assay }(3 \mathrm{ml})}{\mathrm{E} \times \mathrm{mg} \text { of protein }}
$$

Where $\mathrm{R}=$ Rate of enzyme activity in ' $\mathrm{n}$ ' mole of acetylcholine iodide hydrolyzed/minute/mg protein. $\delta$ O.D. $=$ Change in absorbance $/ \mathrm{min}$ and $\mathrm{E}=$ Extinction coefficient $=13600 / \mathrm{M} / \mathrm{cm}$.

Statistical Analysis — All the results were expressed as mean \pm Standard error. The data was analyzed using Analysis of variance (ANOVA) followed by Tukey-Kramer test. $p<0.01$ was considered as statistically significant.

\section{RESULTS}

\section{Effect on TL Using Elevated Plus Maze}

Aged mice showed higher TL values on first day and on second day (after $24 \mathrm{hr}$ ) as compared to young mice, indicating impairment in learning and memory (i.e. ageing-induced amnesia). Piracetam $(200 \mathrm{mg} / \mathrm{kg}$, i.p.) treatment for 6 days decreased transfer latency on $6^{\text {th }}$ day and after $24 \mathrm{hr}$ i.e. on $7^{\text {th }}$ day as compared to control group, indicating improvement in both learning and memory. Scopolamine $(0.4 \mathrm{mg} / \mathrm{kg}$, i.p. $)$ and Diazepam $(1 \mathrm{mg} / \mathrm{kg}$, i.p.) increased TL significantly ( $p<0.01)$ in young mice on first and second day as compared to control, indicating impairment of memory.

AS (100 and $200 \mathrm{mg} / \mathrm{kg}$, p.o.) decreased the TL on $6^{\text {th }}$ day and $7^{\text {th }}$ day in young and aged mice $(p<0.01)$ when compared to control groups. Higher dose of AS (200 mg/kg, p.o.) more significantly enhanced the learning and memory of aged animals rather than the young mice as reflected by marked decrease in TL on $6^{\text {th }}$ day and $7^{\text {th }}$ day when subjected to elevated plus maze tests (Fig. 1). The higher dose of AS pretreatment for 6 days successively to young mice protected them $(p<0.01)$ against scopolamine, diazepam and ageing induced amnesia (Fig. 2).

\section{Effect on SDL Using Passive Avoidance Appara- tus}

AS (200 mg/kg, p.o.) profoundly increased SDL significantly as compared to control group on second day indicating improvement in memory of young mice (Fig. 3). Furthermore, this dose of AS reversed diazepam, scopolamine induced amnesia as well, like in the elevated plus maze model 


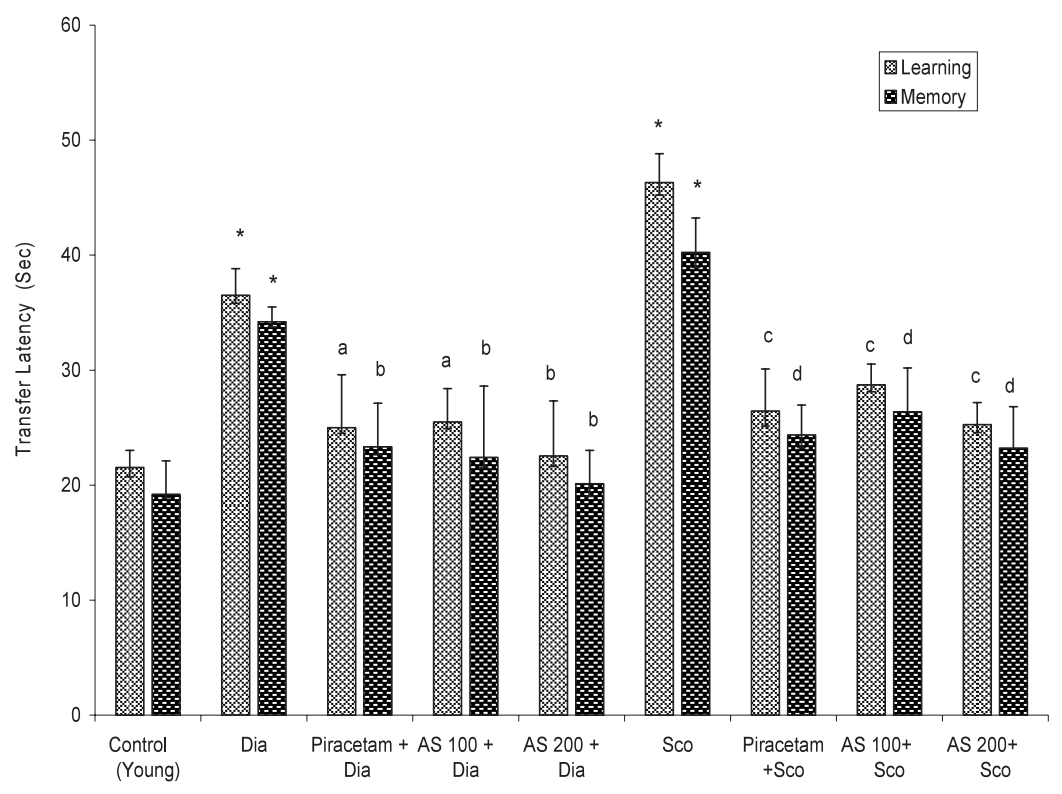

Fig. 2. Effect of AS on TL in Scopolamine and Diazepam Induced Amnesia. Piracetam $(200 \mathrm{mg} / \mathrm{kg}$, i.p.) was Used as Standard Drug Values are Mean $\pm \operatorname{SEM}(n=5)$, ANOVA followed by Tukey-kramer test, $a) p<0.01$ compared to diazepam, $b) p<0.001$ compared to diazepam, c) $p<0.01$ compared to scopolamine, $d$ ) $p<0.001$ compared to scopolamine. $* p<0.01$ compared to control (young mice).

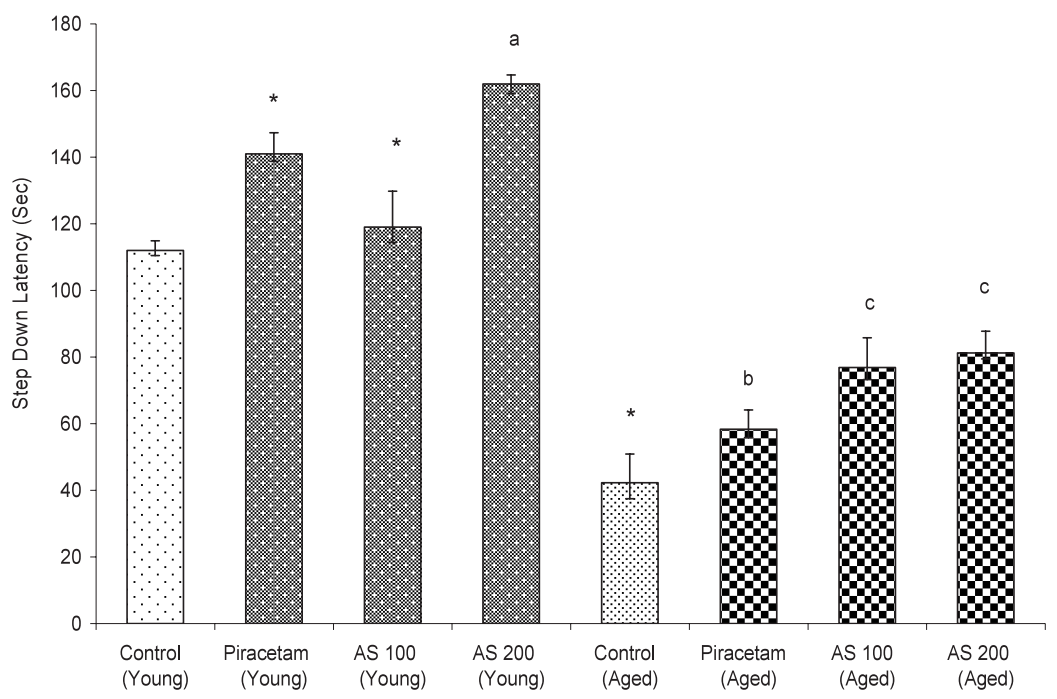

Fig. 3. Effect of AS on SDL of Young and Aged Mice. Piracetam ( $200 \mathrm{mg} / \mathrm{kg}$, i.p.) was Used as Standard Drug

Values are Mean $\pm \operatorname{SEM}(n=5)$, ANOVA followed by Tukey-kramer test, ${ }^{*} p<0.01$ compared to control (Young mice), $\left.a\right) p<0.001$ compared to control (Young mice), $b$ ) $p<0.01$ compared to control (Aged mice), $c) p<0.001$ compared to control (Aged mice).

(Fig. 4). Diazepam and scopolamine significantly decreased SDL on second day, indicating impairment of memory. AS $(200 \mathrm{mg} / \mathrm{kg}$, p.o.) administered orally for 6 days significantly reversed amnesia induced by diazepam, scopolamine and natural aging (Fig. 4).

\section{Effect on Whole Brain Abbreviation Activity}

The whole brain AChE activity with phenytoin $(12 \mathrm{mg} / \mathrm{kg}$, i.p.) exhibited significant elevation to
AChE activity as compared to control and piracetam ( $200 \mathrm{mg} / \mathrm{kg}$, i.p.). AS (100 and $200 \mathrm{mg} / \mathrm{kg}$, p.o.) significantly reduced AChE activity (Fig. 5).

\section{DISCUSSION}

Alzheimer's is a major public health challenge since the median age of the industrialized world's population is increasing gradually. $\mathrm{AD}$ has been 


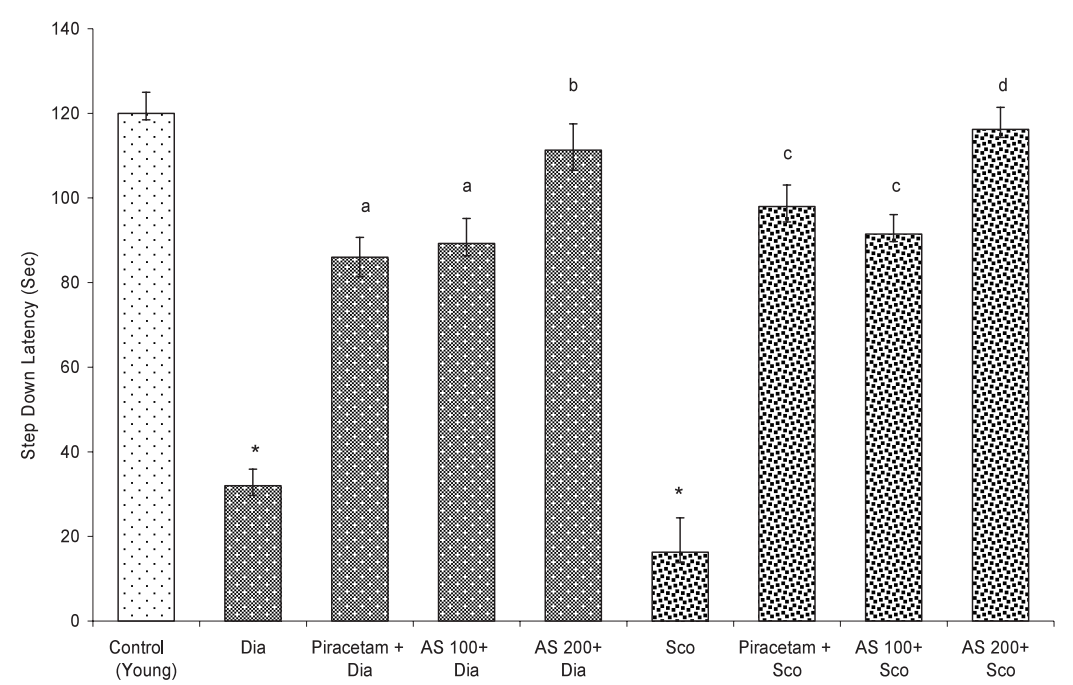

Fig. 4. Effect of AS on SDL in Scopolamine and Diazepam Induced Amnesia. Piracetam (200 mg/kg, i.p.) was Used as Standard Drug Values are Mean $\pm \operatorname{SEM}(n=5)$, ANOVA followed by Tukey-kramer test, $a) p<0.01$ compared to diazepam, $b) p<0.001$ compared to diazepam, c) $p<0.01$ compared to scopolamine, $d) p<0.001$ compared to scopolamine. $* p<0.01$ compared to control (young mice).

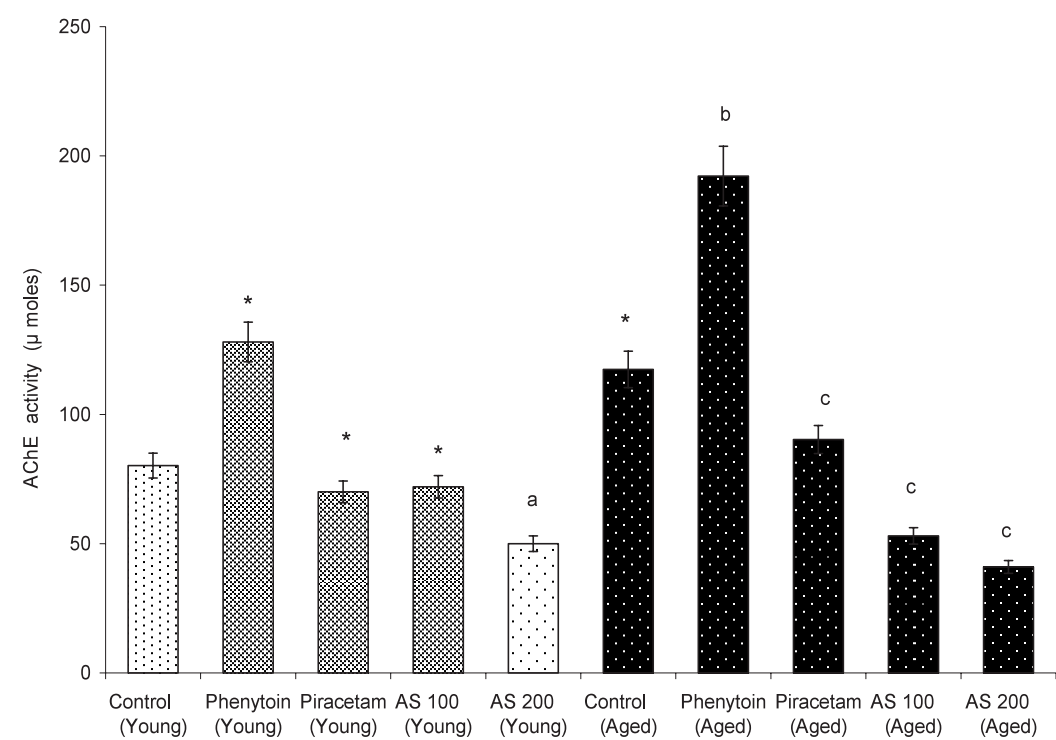

Fig. 5. Effect of AS on AChE Activity of Young and Aged Mice. Piracetam ( $200 \mathrm{mg} / \mathrm{kg}$, i.p.) was Used as Standard Drug. Phenytoin was the Negative Control

Values are Mean $\pm \operatorname{SEM}(n=5)$, ANOVA followed by Tukey-kramer test, ${ }^{*} p<0.01$ compared to control (Young mice), $\left.a\right) p<0.001$ compared to control (Young mice), $b$ ) $p<0.01$ compared to control (Aged mice), c) $p<0.001$ compared to control (Aged mice).

identified as a protein misfolding disease due to the accumulation of abnormally folded amyloid beta protein in the brains of $\mathrm{AD}$ patients. ${ }^{16)}$ In $\mathrm{AD}$ patients, hyperphosphorylated tau accumulates as paired helical filaments, ${ }^{17)}$ that in turn aggregate into masses inside nerve cell bodies known as neurofibrillary tangles. The National Institute of Health predicts, if the current trend continues, there will be more than 8.5 million AD patients by the year 2030 in U.S.A. alone. ${ }^{18)}$ Oxidative damages, im- paired neurotransmission and degeneration of neurons lead to irreversible decline in cognitive abilities, treatment with nootropics such as piracetam, pramiracetam, aniracetam and choline esterase inhibitors like donapezil and tarcine have not been successful for long term therapy due to their adverse effects. ${ }^{19,20)}$

Current treatments for $\mathrm{AD}$ have only moderate symptomatic effects on the disease. ${ }^{21)}$ The present study indicates that AS is a potential anti- 
cholinesterase agent. It also possesses nootropic activity in view of its facilitatory effect on retention of acquired learning. AS decreased transfer latencies, increased SDL in mice when subjected to passive avoidance paradigm, indicating its potent anti amnesic activity. AS also reversed the diazepam, scopolamine and ageing-induced memory impairments. Central cholinergic system plays an important role in learning and memory. ${ }^{22)}$ Phenytoin is known to reduce hippocampal AChE concentration $^{23)}$ and causes cognitive impairment. ${ }^{24)}$ In our study, phenytoin per se $(12 \mathrm{mg} / \mathrm{kg}$, i.p. $)$ significantly elevated brain AChE activity. Piracetam (200 mg/kg, i.p.) and AS (100 and $200 \mathrm{mg} / \mathrm{kg}$, p.o.), on the other hand significantly ( $p<0.01$ ) lowered this activity indicating the counteracting action of the two drugs on the cholinergic system. Pretreatment with aqueous extract of AS (100 and $200 \mathrm{mg} / \mathrm{kg}$, p.o.) for 6 days significantly reduced TL time of young mice and more profoundly in aged mice compared to control and piracetam treated standard groups of mice. The aqueous extract of AS elicited profound neuroprotective effect in diazepam, scopolamine treated and older mice compared to control groups and piracetam treated mice. It significantly inhibited AChE activity in the whole brain homogenate of mice indicating its potential in the attenuation of learning and memory deficits especially in the aged mice. AS significantly reversed amnesia induced by diazepam, scopolamine which probably indicated that AS potentiated memory and learning especially in diazepam scopolamine induced amnesic mice. Considering the lack and the need of the drugs with proven effectiveness in improving learning and memory the specific memory improving and anticholine esterase effect of AS can be of enormous interest for further investigations.

Kindly change as per JHS rule, since AS (100 and $200 \mathrm{mg} / \mathrm{kg}$, p.o.) elicited profound neuroprotective effect in diazepam, scopolamine treated and aged mice compared to control groups and piracetam treated groups, it can be used for the management of $\mathrm{AD}$ and other cognitive disorders. However, investigations using more experimental paradigms may be warranted for further confirmation of nootropic potential of AS in the treatment of dementia and AD.

Acknowledgements The authors express deep sense of gratitude to the management, SET's College of Pharmacy, Dharwad, Karnataka for providing the facilities. The authors are also thankful to Ranbaxy, India, for the generous supply of diazepam, UCB pvt. Ltd., India, for supply of piracetam and Zydus Neurosciences, India for the supply of phenytoin.

\section{REFERENCES}

1) Lee, V. M. and Trojanowski, J. Q. (1992) The disordered neuronal cytoskeleton in Alzheimer's disease. Curr. Opin. Neurobiol., 2, 653-656.

2) Glener, G. C. and Wong, C. W. (1984) Alzheimer's disease and Down's syndrome: sharing of a unique cerebrovascular amyloid fibril protein. Biochem. Biophys. Res. Commun., 122, 1131-1135.

3) Hebert, L. E., Scherr, P. A., Bienias, J. L., Bennett, D. A. and Evans, D. A. (2003) Alzheimer disease in the US population: prevalence estimates using the 2000 census. Arch. Neurol., 60, 1119-1122.

4) Joshi, H. and Parle, M. (2006) Nardostachys jatamansi improves learning and memory in mice. $J$. Med. Food., 9, 113-118.

5) Kirtikar, K. R. and Basu, B. D. (1994) Indian Medicinal Plants, Shiva Offset Press, Dehra Dun, pp.1707-1709.

6) Gokhale, A. B., Damre, A. S., Kulkarni, K. R. and Saraf, M. N. (2002) Preliminary evaluation of antiinflammatory and anti-arthritic activity of S. lappa, A. speciosa and A. aspera. Phytomedicine., 9, 433437.

7) Gokhale, A. B., Damre, A. S. and Saraf, M. N. (2003) Investigations into the immunomodulatory activity of Argyreia speciosa. J. Ethnopharmacol., 84, 109-114.

8) Borsutzky, M., Passie, T., Paetzol, W., Emrich, H. M. and Schneider, U. (2002) Hawaiian baby woodrose: (Psycho-) Pharmacological effects of the seeds of Argyreia nervosa [A case-orientated demonstration]. Nervenarzt, 73, 892-896.

9) Joshi, H. and Parle, M. (2006) Antiamnesic Effects of Desmodium gangeticum in Mice. Yakugaku Zasshi., 126, 14-17.

10) Dhingra, D., Parle, M. and Kulkarni, S. K. (2004) Memory enhancing activity of Glycyrrhiza glabra in mice. J. Ethnopharmacol., 1, 361-365.

11) Itoh, J., Nabeshima, T. and Kameyama, T. (1990) Utility of an elevated plus maze for the evaluation of nootropics, scopolamine and electro convulsive shock. Psychopharmacology, 101, 27-33.

12) Parle, M. and Dhingra, D. (2003) Ascorbic acid: a promising memory enhancer in mice. J. Pharmacol. Sci., 93, 129-135.

13) Joshi, H. and Parle, M. (2005) Effects of piperine 
on memory and behavior mediated via monoamine neurotransmitters. J. Trad. Med., 2, 39-43.

14) Joshi, H. and Parle, M. (2006) Brahmi rasayana Improves Learning and Memory in Mice. eCAM, 3, 79-85.

15) Ellman, G. L., Courtney, K. D., Valentino, A. J. and Featherstone, R. M. (1961) A new and rapid colourimetric determination of acetylcholinestrase activity. Biochem Pharmacol., 7, 88-95.

16) Hashimoto, M., Rockenstein, E., Crews L. and Masliah, E. (2003) Role of protein aggregation in mitochondrial dysfunction and neurodegeneration in Alzheimer's and Parkinson's diseases. Neuromolecular Med., 4, 21-36.

17) Goedert, M., Klug, A. and Crowther, R. (2006) Tau protein, the paired helical filament and Alzheimer's disease. J. Alzheimers Dis., 9 (3 Suppl), 195-207.

18) National Institute of Aging and National Institutes of Health. (2000) Progress report on Alzheimer's disease: Taking the steps. National Institute of Aging-National Institutes of Health, Washington D.C., pp.126-134.

19) Rogers, S. H., Farlow, M. R., Doody, R. S., Mohs, R. and Friedhoff, L. I. (1998) Donepezil study group. A 24-week, double blind, Placebo-controlled trial of donepezil in patients with Alzheimer's disease. Neurology, 50, 136-145.

20) Joshi, H. and Parle, M. (2006) Evaluation of nootropic potential of Ocimum sanctum Linn in mice. Ind. J. Exp. Biol., 44, 133-136.

21) Gasparini, L., Ongini, E. and Wenk, G. (2004) Non-steroidal anti-inflammatory drugs (NSAIDS) in Alzheimer's disease: Old and new mechanisms of action. J. Neurochem., 91, 521-536.

22) Biegon, A., Greenberger, V. and Segal, M. (1986) Quantitative histochemistry of brain acetyl cholinesterase and learning in the aged rat. Neurobiol. Aging, 7, 215-217.

23) Agarwal, S. L. and Bhargava, V. (1964) Effect of drugs on brain acetylcholine level in rats. Ind. $J$. Med. Res., 52, 1179-1182.

24) Aldenkamp, A. D., Alpherts, W. C. J., Diepman, L., Vantslot, B., Overweg, J. and Vemenlen, J. (1994) Cognitive side effects of phenytoin compared with carbamazepine in patients with localization-related epilepsy. Epilepsy Res., 19, 37-43.

25) Sengupta, S. and Chattopadhyay, M. K. (1993). Lowry's method of protein estimation: some insights. J. Pharm. Pharmacol., 45, 80-84. 